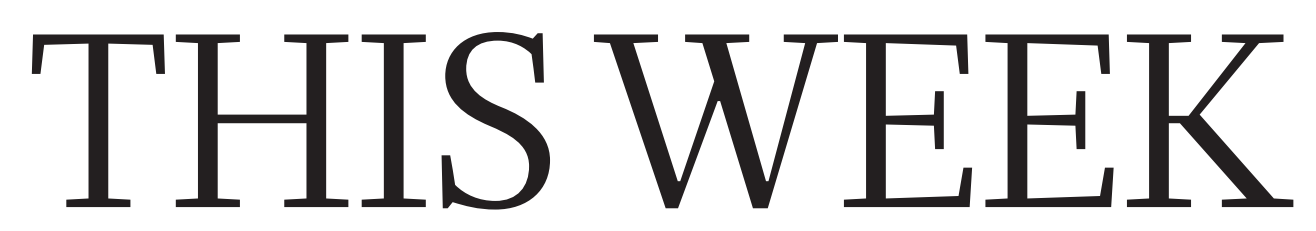

EDITORIALS

TASTY The shifting

future of food safety

checks p.476
WORLD VIEW The haze stopping

indigenous people from

benefiting from science $\mathbf{p . 4 7 7}$
SHOCKING How electric eels make sense of their prey $\mathbf{p . 4 7 9}$

\title{
Russian roulette
}

\author{
Attempts to keep foreign interests out of Russian research will only suppress the exchange of \\ information, and risk damaging East-West relations.
}

$\mathrm{D}$ espite decades of intellectual isolation, the Soviet Union produced some fine science. When it imploded, only a wave of foreign aid and philanthropy protected that excellent research base from collapse. The strategy worked: as individualism and entrepreneurship took hold in Russia, science regained its strength and started to look outwards - as any successful research endeavour must in the twenty-first century.

Yet Russian President Vladimir Putin believes that his country can increasingly go its own way, and centralism and anti-Western rhetoric are on the rise. Science is beginning to suffer from paranoid state control.

As we report on page 486, Russia has placed strict new rules on how its scientists can operate. In response to a recently amended law, Russian universities and research institutes have begun to instruct scientists to seek permission from the Federal Security Service before they submit papers or give talks at scientific conferences..

The wording of the law is vague, seemingly deliberately so. It effectively requires any work that is applicable to industry to be approved for publication. Russian scientists are rightly outraged by this return to inglorious Soviet practices.

Meanwhile, dozens of organizations that receive foreign funding (and which the Russian government suspects are involved in "political activities" - again vaguely defined) are under scrutiny. Officially, this is to identify and repel unwelcome foreign influence. Unofficially, there is a whiff of political scores being settled.

In May, the Dynasty Foundation, Russia's largest private sciencefunding organization, shut down after the Ministry of Justice labelled it a "foreign agent". Other philanthropic groups and foreign-funded foundations fear that they may soon find themselves on a list of "undesirable" organizations that the Russian parliament is drawing up.

This is not the 1960s. Today, fear and isolationism can only damage collaborative science. In turn, this will undermine Russia's efforts to modernize its struggling economy. Putin knows only too well that his country's dependence on oil and gas exports is a treacherous anachronism as the world steers away from fossil-fuel use. Wisely, the government has substantially stepped up its science funding in recent years. But neither a multibillion-rouble nanotechnology initiative, launched in 2007, nor attempts to create a number of world-class research universities and attract top Western scientists to Russian labs will bear fruit if fear and distrust continue to stand in the way of a liberal science culture.

Russia's annexation of the Crimean Peninsula last year, and its dubious role in the ongoing conflict in the rest of Ukraine, chilled East-West collaborations, in science and other fields. Russia's controversial military involvement in the civil war in Syria, although cautiously tolerated by Western powers, threatens to cause further tension.

Through large European research facilities such as the particlephysics laboratory CERN and the international nuclear-fusion project ITER, science can still offer a much-needed peaceful counterbalance in these politically turbulent times. But a disturbingly anti-Western speech to the upper chamber of the Russian parliament by Putin's top science adviser on 30 September - the same day that Russia began its air strikes in Syria - testifies to the level of misunderstanding that is currently poisoning East-West relations across the board.

The speech by Mikhail Kovalchuk, director of the Kurchatov Institute of nuclear science in Moscow and a key contact for many international collaborations, delivered a patently absurd account, "A crackdown
on academic
freedom
and foreign
support will be
devastating." riddled with lies and propaganda, of how international science is a US plot to undermine Russia. Such anti-Western sentiments are readily echoed in Russia: last week, a high-ranking IT adviser to the government said that Russia should stop training computer experts because they will before long be serving Western interests.

Making a bogeyman of the outside world - and in particular of the United States - is a populist political strategy intended to prepare the ground for anti-liberal isolationism. For Russia's scientific community, a crackdown on academic freedom and foreign support will be devastating. Putin, who frequently expresses his appreciation of science, must see that investment alone is not enough.

To pour cash into a system that stifles intuition, brilliance and truth will not help a nation that has always held scientists and explorers in great esteem. Even through difficult economic and political times, Russian science has produced a never-ending supply of great minds. It needs the freedom and respect to continue to do so..

\section{Abstract thoughts}

\section{Scientists, meeting organizers and the media must take care with preliminary findings.}

$\mathrm{T}$ The rough and tumble of professional science is no place for the faint-hearted. Progress rests on honest appraisal of methods and results. Ideas must be challenged and conclusions defended. One of the most important transitions for any researcher is swapping the textbook scrutiny of the undergraduate years for critical and creative thinking. At the centre of this culture is the academic conference.

Often the first chance for studies to be presented, discussed and criticized, these meetings are an important testing ground for early research. The community gets a heads-up on what others are doing, and how, and the scientists involved get some robust feedback that can shape their work. 